\title{
Formação Docente para a Educação Pré-Escolar na Época da Ditadura Militar
}

\author{
Ana Maria Orlandina Tancredi Carvalho' \\ 'Universidade Federal do Pará (UFPA), Belém/PA - Brasil
}

RESUMO - Formação Docente para a Educação Pré-Escolar na Época da Ditadura Militar. Este artigo reflete sobre a formação docente para a Educação Pré-Escolar, no período da Ditadura Militar. Pesquisei a Revista Criança, publicação oficial do Ministério da Educação, primeiro periódico nacional para a área. A pesquisa bibliográfica e documental ocorreu de 2003 a 2006, durante meu doutoramento, em legislações, documentos, e na própria Revista, publicada nos anos de 1982 a 1985, e entrevistas com técnicos. São 14 revistas que serviram de veículo da política de formação desse período, apoiada na teoria do capital humano que no campo educacional se expressa por meio de uma pedagogia tecnicista. A Revista não questiona o preconceito contra os pobres, nem o autoritarismo e antecipa a escolarização das crianças da Educação Pré-Escolar.

Palavras-chave: Formação de Professores. Revista Criança. Educação Pré-Escolar.

ABSTRACT - Teacher Education for Preschool Education during the Era of the Military Dictatorship. This article analyzes teacher formation for pre-school education in the period of the military dictatorship. I have conducted our research in Revista Criança, an official publication of the Ministry of Education, first national journal for this field. Our bibliographical and document research took place from 2003 to 2006 - period of my $\mathrm{PhD}$, taking as the base for this research: legislation, documents, interviews and the Magazine itself, published between 1982 and 1985. Fourteen magazines served as basis for this education policy within that period, supported on the Theory of Human Capital, which, in the education field, is expressed through technicist pedagogy. The magazine does not question the prejudice against the poor people nor the authoritarianism and anticipates the education for children in pre-school education.

Keywords: Teacher Education. Revista Criança. Preschool Education.

Educação \& Realidade, Porto Alegre, v. 40, n. 4, p. 1061-1075, out./dez. 2015.1061 http://dx.doi.org/10.1590/2175-623651546 
Formação Docente para a Educação Pré-Escolar na Época da Ditadura Militar

\section{Introdução}

Este artigo analisa a constituição de uma das primeiras políticas de formação docente para a Educação Infantil, tendo como fonte de investigação a Revista Criança, publicação oficial do Ministério da Educação, primeiro periódico de abrangência nacional para o nível hoje denominado Educação Infantil ${ }^{1}$ e que, nas publicações oficiais do Ministério da Educação - diagnósticos, planos, programas, bem como na voz corrente dos educadores, denominava-se Educação Pré-Escolar.

A pesquisa resulta de um longo processo de análise realizado entre os anos de 2003 a 2006, por ocasião do doutoramento da autora. Os caminhos investigativos percorridos assentam-se na pesquisa bibliográfica e documental, cujas fontes foram: constituições federais, emendas constitucionais, leis, planos, programas, projetos, pareceres, publicações oficiais e a própria Revista Criança, além de entrevistas realizadas com profissionais que ocupavam cargos na esfera administrativa do Estado Brasileiro, à época da publicação da referida Revista. Delimitamos, para este artigo, as publicações de 1982 (ano que inicia sua circulação) até 1985, somando o total de 14 (quatorze) revistas, todas editadas pelo Movimento Brasileiro de Alfabetização (Mobral), cuja tiragem em outubro desse ano alcançou 32.000 (trinta e dois mil) exemplares².

A pesquisa problematizou o fato de essa publicação ter sido produzida pelo Mobral, programa destinado a alfabetizar jovens e adultos e não crianças. Tal achado propiciou a busca de sentido para tal fato. Por que o Mobral? O referido programa foi criado em 1967, à época da Ditadura Militar, para se contrapor ao Plano Nacional de Alfabetização, instituído em janeiro de 1964, utilizando a pedagogia Freireana que, além de ensinar a ler, escrever e contar, tinha como objetivo a conscientização - objetivo esse incompatível com um regime ditatorial.

O Mobral tinha como objetivo a erradicação do analfabetismo por meio da alfabetização dos adultos.

Vários autores manifestaram-se acerca do objetivo enunciado. Saviani (1984, p. 52), por exemplo, questiona “[...] Quem desconhece as funções econômicas, políticas e ideológicas que vem sendo desempenhadas por este Movimento Brasileiro de Alfabetização [...]?" Cunha (1989, p. 59) afirma que o Mobral "[...] pretendia formar eleitores para o partido do governo autoritário, a Aliança Renovadora Nacional [...]”, além de cumprir uma função ideológica fazendo-se presente nos mais longínquos espaços para vigiar e punir.

O Movimento Brasileiro de Alfabetização foi extinto em 1985.

As pesquisas feitas indicaram que a Revista Criança foi editada em uma época de grandes embates na sociedade brasileira: contra a violência e a subtração de direitos e pela democratização do país, tendo esse periódico se instituído como uma política estratégica da Ditadura Militar para a formação em serviço daqueles e daquelas - inicialmente, de-

1062 Educação \& Realidade, Porto Alegre, v. 40, n. 4, p. 1061-1075, out./dez. 2015. 
nominados monitores, posteriormente professor de educação pré-escolar e, hoje, professor de Educação Infantil - que se habilitavam para atuar com as crianças de baixa renda na Educação Pré-Escolar, utilizando recursos, estrutura e a tecnologia do Mobral (Tancredi Carvalho, 2006).

A gênese da pesquisa que deu origem a este artigo funda-se no valor do respeito em relação ao trabalho realizado por todos/as os/as profissionais que desempenhavam funções técnico-pedagógicas, bem como daqueles/daquelas que se ocupavam das atividades fim, como os/ as monitores/as, pois, não raras vezes, ignoravam as manobras políticas e os objetivos não proclamados de quem detém o poder. A pesquisa, entretanto, evidencia as ambiguidades, as contradições, os embates entre diferentes concepções teóricas e forças políticas em disputa que transparecem na publicação, assim como a discriminação relativa às crianças oriundas das camadas populares.

Ante o exposto, procura-se responder às perguntas: Como surge a Revista Criança? Constitui-se esta revista como uma das primeiras políticas de formação do docente da Educação Pré-Escolar, que políticas de formação eram praticadas? Que impactos a formação tecnicista teve na educação das crianças de 0 a 6 anos de idade?

\section{Contexto Histórico da Revista Criança}

Tardiamente o Estado Brasileiro reconhece a educação como um direito do cidadão, tornando-a obrigatória, tendo isso acontecido pela primeira vez com a Constituição de 1934, quando, em função dos processos de urbanização e industrialização e do modelo econômico de substituição de exportações (Freitag, 1986), o Brasil precisava de mão de obra minimamente alfabetizada para o nascente parque industrial. Daí a necessidade de tornar obrigatória (de acordo com o Art. 148 da referida Constituição), a Educação como direito de todos e, ainda, o Art. 159 \$ Único, determina que o Plano Nacional de Educação deverá obedecer a seguinte norma constante da alínea a) "o ensino primário integral e de frequência obrigatória, extensivo aos adultos" (Poletti, 2001, p. 168).

No que concerne à educação da criança pequena, na faixa etária de 0 a 6 anos, um longo caminho foi percorrido até que entrasse na pauta de discussão como interesse nacional e direito de todas as crianças, ocorrendo somente com a Constituição Federal de 1988, quando no artigo $7^{\circ}$, alínea XXV estabelece como direito dos trabalhadores sejam eles do meio urbano ou rural "[...] assistência gratuita aos filhos e dependentes desde o nascimento até 5 (cinco) anos de idade em creches e pré-escolas (Redação dada pela Emenda Constitucional no 53, de 2006, online)" que no capítulo referente à educação no artigo 208 dessa Carta Constitucional assegura a todos o direito à educação e dever do Estado, reforçando que esse dever se efetiva mediante a oferta da educação infantil em creche e pré-escolas às crianças de 0 a 5 anos de idade, artigo esse também modificado pela Emenda Constitucional 53 (Brasil, 2014).

Educação \& Realidade, Porto Alegre, v. 40, n. 4, p. 1061-1075, out./dez. 2015.1063 
Formação Docente para a Educação Pré-Escolar na Época da Ditadura Militar

Também tardiamente, foi introduzido no organograma do Ministério da Educação um órgão que se ocupasse da educação das crianças pequenas. Isso correu em 1974, tendo recebido as seguintes denominações ao longo de sua história: Setor de Educação Pré-Escolar (Sepre), que se transforma em Coordenação de Educação Pré-Escolar (Codepre), posteriormente em Coordenadoria de Educação Pré-Escolar (Coepre) e em 1992 transforma-se em Coordenadoria de Educação Infantil (Coedi) mantendo essa terminologia e sigla até a presente data.

As políticas educacionais na vigência do golpe militar objetivavam adaptar-se ao modelo econômico e à doutrina da segurança nacional e são influenciadas pelas agências internacionais como United States Agency for International Development, cujos acordos tornaram-se conhecidos no país como Acordos MEC-USAID. Programas estadunidenses, como o Head Star na Educação Pré-Escolar fundamentavam-se na teoria da privação cultural e nos programas de educação compensatória, resultando para a Nação Brasileira em planos e programas com políticas focadas, de caráter emergencial, não formal, que discriminam as camadas populares, visto que do ponto de vista conceitual nessa proposta é atribuído às crianças provenientes deste segmento populacional: carências socioculturais, alimentares, deficiências linguísticas, cognitivas entre outras. Todavia estes planos não garantem nem a inclusão no sentido de atender a demanda, nem a educação infantil de qualidade e nem interferem na organização do sistema de ensino no sentido alterar os níveis de educação e desigualdade na oferta garantindo a democratização do acesso (Tancredi Carvalho, 2006).

Estes programas para esse nível de educação da época da Ditadura Militar integravam a área social, e pela sua capilaridade, visto que alcançam as mais longínquas localidades, exerciam o controle da população, identificando focos de resistência ao regime, implementando a doutrina da segurança nacional. Referidos programas antecipavam a escolarização, visto que a pré-escola possuía ainda esse propósito, evitar um mal maior, qual seja o comprometimento de aprendizagens futuras e o fracasso da escola. Estes programas eram desenvolvidos em espaços ociosos da comunidade, a família era convocada para o trabalho, em geral voluntário. As atividades junto às crianças eram realizadas por pessoas que não eram profissionais da área, contavam com baixo investimento público e excluíam a zona rural, constatação feita por Rosemberg (2003) quando se pronuncia em relação aos princípios e modelos sugeridos aos países subdesenvolvidos para a Educação Infantil, no período (1970-1990) pelos organismos internacionais como o Unicef e a Unesco.

[...] a expansão da EI constitui uma via para combater a pobreza (especialmente, desnutrição) no mundo subdesenvolvido e melhorar o desempenho do ensino fundamental; portanto, sua cobertura deve crescer; os países pobres não dispõem de recursos públicos para

1064 Educação \& Realidade, Porto Alegre, v. 40, n. 4, p. 1061-1075, out./dez. 2015. 
expandir, simultaneamente, o ensino fundamental (prioridade número um) e a EI;

a forma de expandir a EI nos países subdesenvolvidos é através de modelos que minimizem investimentos públicos, dada a prioridade de universalização do ensino fundamental;

para reduzir os investimentos públicos, os programas devem apoiar-se nos recursos da comunidade, criando programas denominados 'não formais', 'alternativos', 'não institucionais', isto é, espaços, materiais, equipamentos e recursos humanos disponíveis na 'comunidade', mesmo quando não tenham sido concluídos ou preparados para esta faixa etária e para seus objetivos (Rosemberg, 2003, p. 180).

É nesse contexto que é elaborado em 1975 um Diagnóstico Preliminar da Educação Pré-Escolar, no qual informa que $60 \%$ das crianças são carentes econômica e socialmente (Brasil, 1987) e com base nesse Diagnóstico elabora-se o Programa Nacional de Educação Pré-Escolar, lançado em 1981, coordenado pelo Ministério da Educação por meio da Coepre que implanta uma série de medidas já citadas anteriormente, visando expandir as vagas a baixo custo com o trabalho voluntário das mães e em espaços disponíveis na comunidade.

Para alcançar os objetivos propostos, o MEC/Coepre firma convênios com as Secretarias de Educação dos Estados e convoca o Mobral, acrescentando outro objetivo a este Movimento, qual seja prestar atendimento às crianças de baixa renda, na faixa etária de 4 a 6 anos para desenvolver a Educação Pré-Escolar. Desse modo o programa atuava por meio das Secretarias de Educação das Unidades Federadas para as crianças que frequentam as escolas públicas e do Movimento Brasileiro de Alfabetização, para as camadas empobrecidas da sociedade.

Destaca-se que, à época, o Mobral já apresentava sinais de esgotamento de seus objetivos enquanto instituição, sendo alvo de contestação pública, quer por não ter cumprido os objetivos para os quais foi criado - pois de acordo com o Censo de 1980, o índice de analfabetismo, na faixa etária de 15 anos e mais, era de $25 \%$, quando se esperava que o mesmo fosse em torno de $10 \%$ - quer pelo descompasso entre os objetivos reais e os objetivos proclamados, quer mesmo pelo Congresso Nacional, que instala uma Comissão Parlamentar de Inquérito.

O Senador João Calmon (1991, p. 24-25) assim se manifesta,

[...] o Mobral foi alvo de uma iniciativa minha, pois aos poucos ele fora se desviando de sua proposta original, ingressando em novos campos. Considerei inaceitável, por exemplo, a criação, por decisão de seus próprios dirigentes, de um Mobral infanto-juvenil, para criança entre dez e 14 anos de idade, que concorreria diretamente com a escola regular. Denunciei essa aberração da tribuna do Senado. Foi pedido então pelo Senador Franco Montoro,

Educação \& Realidade, Porto Alegre, v. 40, n. 4, p. 1061-1075, out./dez. 2015.1065 
baseando-se na minha denúncia, a formação de uma Comissão Parlamentar de Inquérito para investigar a ação do Mobral. [...]. O resultado dessa CPI foi extremamente chocante porque cada depoimento equivalia à abertura de uma cloaca, tais eram as irregularidades, os desvios e as distorções do Mobral.

O Mobral leva para a Educação Pré-Escolar a metodologia adotada nos seus programas de alfabetização caracterizados por utilizar espaços ociosos na comunidade como escolas, clubes, igrejas, centros de cultos, fábricas, quartéis, galpões; os recursos humanos, em geral, não profissionalizados, denominados de monitores, voluntários ou com baixa remuneração, a sucata como material a ser usado pelas crianças e baixo investimento público - prática, aliás, corrente quando se trata de política dirigida aos segmentos de menor poder aquisitivo da população, ao qual a classe dominante impõe uma educação pobre para o pobre, pois, de acordo com Kuhlmann Junior (1998), objetiva educar para a submissão.

Para desincumbir-se de sua função com as crianças da pré-escola e considerando que o trabalho seria desenvolvido por monitores que nem sempre possuíam a devida qualificação para o desempenho de suas funções, o Mobral cria a Revista Criança, como "[...] instrumento de formação continuada de monitoras do programa [...]” (Leite Filho, 2006, entrevista) ou ainda segundo Didonet (2006, entrevista) "Foi criada como instrumento de informação, formação e apoio aos professores e monitores [...]". Daí, neste artigo a Revista ser considerada como uma das primeiras políticas de formação e de práticas pedagógicas para a Educação Infantil.

Conclui-se, portanto, que o Mobral inclui-se entre os órgãos que publica a Revista Criança pelo fato de já atuar na Educação Pré-Escolar, incumbência que lhe foi atribuída pelo Ministério da Educação e para desincumbir-se dessa atribuição, tendo em vista que irá trabalhar com monitores, cria a Revista Criança como instrumento de formação em serviço.

\section{A Revista Criança como Publicação}

O lançamento de uma revista é sempre um momento cultural significativo, de grande expectativa, especialmente quando a temática é a educação, tendo como alvo as crianças até seis anos numa época em que não havia qualquer periódico sobre criança, infância ou educação das crianças pequenas. Sobre o assunto Didonet (2006, entrevista) revela em entrevista a signatária deste artigo que "[...] o mundo editorial ainda não havia despertado para a educação infantil, os livros eram poucos, e menor ainda o número de revistas, sendo estas locais e de tiragem restrita [...]", no que foi referendado por Kramer (2006, entrevista) quando afirma que "Não havia naquele momento nenhum veículo,

1066 Educação \& Realidade, Porto Alegre, v. 40, n. 4, p. 1061-1075, out./dez. 2015. 
nenhuma publicação periódica pública ou privada voltada à chamada educação pré-escolar [...]".

A Revista Criança, conforme já enfatizamos é o primeiro periódico, de circulação nacional, voltado para a Educação Pré-Escolar, no Brasil, cuja edição de lançamento é de maio/junho de 1982, sendo distribuída gratuitamente aos monitores e professores das instituições públicas da Educação Pré-Escolar.

Nessa época a sociedade brasileira vivia um período de muitos conflitos, pois, boa parte da população, especialmente os movimentos sociais que entram na cena política como atores fundamentais no processo de democratização do país, lutava pelo término da Ditadura Militar, da qual já se vislumbrava o seu fim, porém, havia ainda forte impacto na educação das políticas praticadas nesse período, como as políticas compensatórias para a Educação Pré-Escolar. Esta publicação é uma possibilidade de formação dos monitores, mediante a modalidade treinamento em serviço, tendo a Revista Criança, de acordo com Kramer (2006) veiculado o pensamento político-pedagógico da época.

O objetivo para o qual a Revista Criança foi criada, segundo o presidente do Mobral, era de "[...] contribuir para o aperfeiçoamento do trabalho com as crianças [...]" e ainda "[...] contribuir para a melhoria do trabalho do monitor" (Brasil, 1982, p. 1) tendo, portanto, como interlocutor nos anos de 1982 e de 1983 o monitor. Nos anos de 1984 e 1985 é o monitor do pré-escolar. Sua distribuição posteriormente espraia-se para toda área da Educação Pré-Escolar do Brasil (Tancredi Carvalho, 2006).

Pode-se afirmar que as contradições existentes na Revista Criança iniciam-se desde a primeira página, pois lá registra-se que há uma prioridade nacional em relação à criança todavia as autoridades constituídas da época da Ditadura Militar deste país, no que concerne à Educação Pré-Escolar atribuem-lhe, pouca ou nenhuma importância, visto que a execução desta proposta educacional recai sobre o monitor e não sobre o/a professor/a, ou seja, alguém que não tinha a habilitação necessária e nem atendia as exigências legais para o exercício do magistério em turmas de Educação Pré-Escolar. Acrescente-se ainda que se praticava uma educação compensatória com forte participação da comunidade, com aproveitamento dos espaços disponíveis, na sua grande maioria inadequados para a educação de crianças pequenas, não raras vezes com trabalho voluntário e com a aplicação de recursos reduzidos para as atividades-fim, que é quem garante a realização do trabalho na educação pré-escolar, seguindo, portanto, orientações dos organismos internacionais. Sobre esta matéria, Rosemberg (1992, p. 25) assim se pronuncia:

Esse programa (o pré-escolar) absorveu, na sua totalidade, as recomendações do UNICEF e da UNESCO: educação, nutrição e saúde deveriam ser atendidas de forma

Educação \& Realidade, Porto Alegre, v. 40, n. 4, p. 1061-1075, out./dez. 2015.1067 
Formação Docente para a Educação Pré-Escolar na Época da Ditadura Militar

integrada: utilização de espaços físicos disponíveis na comunidade; a família e a comunidade fariam parte integrante das atividades de educação pré-escolar, objetivando barateamento dos programas.

Os técnicos do Mobral, conduzidos para desenvolver o Programa Nacional de Educação Pré-Escolar para sua instituição, posicionavam-se criticamente em relação à educação compensatória. Leite Filho (2006, entrevista), a esse respeito, afirma: “[...] em pleno governo militar o que não faltava (sic) dentro desta Fundação Pública Federal eram contradições”. A crítica à educação compensatória pode ser constatada tanto por artigos produzidos (Kramer, 1982; Jobim Souza, 1984) à época, quanto por declarações do próprio Coordenador desse Programa ${ }^{3}$ tal como corroboradas por Kramer (2006, entrevista) quando afirma:

Os discursos do MEC sobre a educação pré-escolar datam da segunda metade dos anos 70 e estiveram relacionados ao ideário da educação compensatória (pareceres do Conselho Federal de Educação). [...] O Mobral foi convidado a - como órgão do MEC - implementar a educação pré-escolar nesta linha ainda em 1980. [...] Mas o Mobral modernizou ou atualizou o seu discurso, incorporando a crítica. Logo em seguida (já no final de 1981) o Mobral não mais falava em compensação de carências. Tal como o do MEC, o discurso era o de que a educação pré-escolar tinha objetivos em si mesma (Kramer, 2006, entrevista).

Os temas abordados pela Revista Criança relacionam-se à educação da criança pequena, destacando-se brinquedos e brincadeiras, artes plástica, musical e dramática, como o teatro de sombra, o teatro de varas e a mímica, recorte e colagem. Artigos de fundo como adaptação da criança na instituição, a organização de turmas com diferentes idades, a alfabetização na pré-escola, preconceito de cor, a criança e a sexualidade, a avaliação na pré-escola, o trabalho diversificado, o medo e etc. também se fazem presentes. Esta Revista aborda ainda, artigos sobre a matemática, ciências, linguagem, muitos artigos sobre a higiene, saúde e nutrição evidenciando um viés de classe da revista. Visto que em 14 números publicados existem 16 artigos sobre higiene, saúde e nutrição que praticamente desaparecem da revista nos números subsequentes, visto que até o número 37 existe apenas um artigo sobre essa temática. Por que isso acontece? São publicações destinadas, em última análise, a esses monitores que irão orientar as atividades para as crianças de baixa renda, cuja ciência médica, por um longo período associou a pobreza à doença, daí a influência médico-higienista eleger a higiene como uma área disciplinar e a infância, especialmente a infância desvalida, para aplicá-la.

\section{A Formação Docente para a Educação Pré-Escolar}

A política de formação docente praticada pelo Regime Militar quando o Mobral passa a atuar na Educação Pré-Escolar tem como principal veículo a Revista Criança.

1068 Educação \& Realidade, Porto Alegre, v. 40, n. 4, p. 1061-1075, out./dez. 2015. 
Para compreendermos que formação era praticada nesse programa, transcreve-se parte de artigos destinados aos monitores para viabilizar a educação das crianças de 0 a 6 anos de idade, de baixa renda, em meio à precariedade que era oferecida e para orientar sua prática docente. Artigos prescritivos não se constituem em exceção nos números objetos deste estudo. É ilustrativo da política praticada pela Revista, o texto abaixo como se pode constatar:

Vanda foi treinada no Programa de Educação Pré-Escolar, e irá atender, diariamente, a 25 crianças de 4 a 6 anos. $O$ bairro onde Vanda trabalha é muito pobre. A Comissão Municipal do Mobral de sua cidade conseguiu uma sala bem ampla, pertencente à paróquia, para ali iniciar as atividades educativas com as crianças. A sala, apesar de grande, estava suja, com algumas telhas quebradas. Nela se prepararia a merenda que o Instituto Nacional de Assistência ao Estudante - INAE - enviaria para a unidade. Vanda verificou que, sozinha, não teria condições de resolver tantos problemas. Visitou os pais das crianças, convidando-os para uma reunião. Na reunião discutiu com eles a necessidade de segurança, higiene e alimentação das crianças. Procurou mostrar a eles, também, que aquele local iria servir de atendimento educativo aos seus filhos. Portanto, seria um local que pertenceria a toda a comunidade.

Como melhorar a situação da 'escolinha'?

Alguns pais entenderam, outros não. Porém, aqueles que perceberam como era importante o que Vanda estava dizendo, resolveram ajudá-la.

Seu Feliciano, pintor profissional, se propôs a pintar a sala. Seu Zeca se ofereceu para consertar o telhado.

Mas... e a tinta? E as telhas? E o tijolo e o cimento para construir a cozinha?

Nesse momento, as mães sugeriram: ‘- E se conseguíssemos algum brinde para fazermos uma rifa?'

Outra lembrou: '- Enquanto não temos dinheiro para construir a cozinha, será que não podemos nos revezar, preparando a merenda das crianças, em nossa própria casa?' (RC no 3 Batista; Batista, 1983, p. 3) ${ }^{4}$.

Vanda foi treinada para o exercício da função docente e não possuía uma sólida formação teórica capaz de orientar, conscientemente, a sua prática para na intencionalidade de seu trabalho educativo, recriar caminhos, possibilitar o imprevisto e não apenas executar tarefas pensadas por outros. Sim, tarefas pensadas por outros, pois os treinamentos eram definidos alhures, pelas equipes técnicas do Mobral.

O excerto acima revela um lugar que mais parece um espaço de indigência do que um ambiente para educar crianças pequenas e demonstra toda a ideologia e a política destinada aos segmentos da população de baixa renda praticada nesse período, revelando a dualidade do 
sistema educacional e o preconceito social, pois a alocação dos equipamentos sociais é feita de acordo com a classe social a que pertence $o$ seu destinatário evidenciando todos os elementos da política praticada durante o regime militar que já foram destacados neste artigo.

O excerto também ressalta que Vanda trabalha em um bairro muito pobre, que as atividades seriam desenvolvidas numa sala da paróquia e que o local pertenceria a toda comunidade. Indaga-se: ao se referir a um bairro pobre trata-se apenas, de uma constatação para expressar que não há saneamento, ruas asfaltadas, posto de saúde etc. ou, de fato, pode-se demonstrar a existência de um viés de classe, indicando que ser pobre é ser inferior para muitos que se configuram como burguesia? Seria esse viés uma estratégia para se estabelecer políticas públicas em função da posição ocupada pelos moradores na estrutura social? Há diferença, para o Estado, entre um bairro pobre ou um bairro rico? Ou como nos dizem Marx e Engels (1998) que o Estado está a serviço da classe dominante e, portanto, serviços básicos de qualidade são direcionados para outros estratos sociais e por isso o poder público não constrói uma sala confortável, bonita, segura, arejada para estas crianças poderem participar, enquanto cidadãs, possuidoras de direitos, das atividades que aí seriam realizadas?

Ao afirmar que o espaço seria de toda comunidade registra-se que a ideologia, nessa afirmação opera por meio da legitimação, usando, como estratégia, a universalização, visando fazer acreditar que esse espaço seria de todos (Thompson, 1995). Ainda que, eventualmente, fosse usado pela comunidade, aquele lugar permanece privado e pertencendo a uma determinada instituição, que não é pública, não sendo, portanto, de todos e de todas.

Destacando a elevada colaboração da comunidade desvela-se a ausência do poder público que ao se isentar de sua responsabilidade transfere para os segmentos da população mais excluídos do acesso aos bens culturais, riqueza e serviços públicos o ônus de construir espaços que assegurem condições básicas para o bem-estar e conforto da criança.

São políticas que se enquadram no ideário neoliberal, pois, reduzem investimentos na área social, editam políticas compensatórias, discriminatórias que reafirmam as relações de dominação e de poder, contribuindo para conformar as camadas de baixa renda ao que é oferecido e ainda protagonizando uma educação para a submissão e para o conformismo enfim para se contentar agora com o refugo e, no futuro, com um lugar subalterno nas relações sociais e no mundo do trabalho.

Em um outro texto, o assunto a ser tratado é a contação de histórias e, para tanto, serão confeccionados alguns animais. Ensina a Revista:

Este é um modelo de boneco de dedo. É um cavalo. Mas, você pode variar, criando outros animais.

1070 Educação \& Realidade, Porto Alegre, v. 40, n. 4, p. 1061-1075, out./dez. 2015. 
Recorte o molde de $\mathrm{n} .1$ em um papel tipo cartolina.

O molde n.2 são as orelhas.

Elas devem ser coladas na cabeça do cavalo [...] (RC, n. ${ }^{\circ} 3$, Brasil, 1983, 4 ${ }^{\text {a }}$ capa).

As Revistas Criança do número 1 até o número 14, com raras exceções, focalizam a formação do monitor no que concerne fundamentalmente ao aspecto técnico pedagógico. Os artigos são de caráter prescritivo numa abordagem que deixa transparecer a pouca ou nenhuma escolarização específica para o exercício do magistério desses monitores. A tônica de formação adotada tem como parâmetro orientações bem detalhadas sobre o fazer pedagógico, mais precisamente como fazer, por exemplo, uma reunião, a construção de um boneco, a confecção de jogos direcionados para sugerir atividades que o monitor deveria fazer na sua unidade.

Tais indicadores integram a matriz teórica da pedagogia liberal tecnicista, que, aliás, predominou no período da Ditadura Militar e que no início dos anos 1980 começou a ser questionada.

A concepção pedagógica liberal tecnicista, apoiada na teoria do capital humano tem como objetivo adequar a educação às exigências do mercado de trabalho, enfatizando a preparação de recursos humanos, veiculando conteúdos que propiciem a adaptação do indivíduo ao mundo do trabalho. Esta concepção serviu de fundamentação aos mentores da ditadura militar para orientar toda a formação para uma profissionalização, conforme a Lei 5.592/71. Manifesta-se ainda pela introdução de termos antes desconhecidos na cultura escolar, mas que são largamente utilizados na Economia como mercado de trabalho, recursos humanos, custo benefício e sobretudo por considerar a educação como um investimento e dessa forma investir na educação pré-escolar, significa evitar um mal maior que seria o fracasso nos níveis posteriores de ensino, sobretudo no ensino de $1^{\circ}$ grau, denominação da época. Tal investimento não significava possibilitar uma educação emancipadora, cidadã e sim preparar mão de obra para as diferentes áreas produtivas.

Observa-se também que a centralidade das atividades está no monitor e não na criança, pois cabe a ele determinar até onde a criança pode ir, como se pode constatar a seguir: "Mas não se esqueça, monitor, de que é preciso dosar essas atividades, de acordo com a idade, os interesses e as fases de desenvolvimento das crianças. E, principalmente, respeitar o ritmo de cada um" (Ferreira, 1983, p. 11).

Esta perspectiva está bem de acordo com a pedagogia liberal tecnicista quando reserva para a professora, no caso monitora, o papel de um técnico que organiza as condições de apreensão da matéria e dos meios que possibilitam a aprendizagem, sem a participação das crianças. Cabe, no entanto à criança receber, apreender, fixar as informações e responder de acordo com o solicitado, portanto não é dispensada à criança a condição de sujeito de sua própria aprendizagem.

Educação \& Realidade, Porto Alegre, v. 40, n. 4, p. 1061-1075, out./dez. 2015.1071 
Na formação do monitor está contida a concepção da Educação Pré-Escolar como antecipadora da escolarização posterior, ou seja, os artigos sempre remetem para um conteúdo curricular disciplinar a ser estudado no nível posterior. Há ainda uma didatização dos diferentes artigos, ou seja, a brincadeira, principal atividade guia da criança na idade pré-escolar, principalmente a brincadeira de faz de conta, não tem uma finalidade em si mesma, mas sim é aproveitada para desenvolver a linguagem, a mente matemática, enfim algum conteúdo curricular, como demonstra o trecho abaixo, extraído da seção Respondendo a sua consulta, no qual a monitora ensinou às crianças o brinquedo cantado Sinhá Marreca e depois orienta a monitora como proceder, como se pode observar a seguir:

\begin{abstract}
Após a brincadeira, você poderá conversar sobre o conteúdo da música. Por exemplo: "A música contou a história de quem? O que a Sinhá Marreca tinha na mão? O que ela estava fazendo? Que é samburá? Que é empada? Como a sinhá marreca estava vestida?

Com essas perguntas, monitor, você estará estimulando a compreensão, a memória e a imaginação das crianças. Ao mesmo tempo em que elas estarão desenvolvendo a linguagem [...] (RC, nº 5, Brasil, 1983, p. 2).
\end{abstract}

Qual é a concepção de formação que temos em mente quando praticamos o ato de educar? $\mathrm{O}$ fato de determinar o que a criança deve ou não deve fazer coloca-a em uma atitude de absoluta passividade, de espera e rebaixa-a na sua relação com o adulto e não permite à criança a possibilidade de se exercitar em tomar decisões ou fazer escolhas. A didatização das atividades é uma prática recorrente ao longo da Revista Criança.

Todas as citações retiradas desse periódico mostram que na sua origem ela nasce com um forte viés de classe, explicitado tanto na razão de sua publicação, como nos textos iconográficos e escritos.

\title{
Considerações Finais
}

Este artigo explicita que a política de formação de professores para a Educação Pré-Escolar implantada durante a Ditadura Militar tem sua origem com a Revista Criança, destinada ao "monitor" do Mobral que ocupa uma função docente, visto que atuava com as crianças de 4 a 6 anos de idade.

A formação dos/as monitores/as tem como matriz política as determinações prescritas pelos organismos internacionais que resultaram em propostas de baixo investimento governamental, desenvolvido em espaços ociosos, com forte apoio da participação comunitária no desenvolvimento trabalho, que não raras vezes era voluntário, portanto com reduzido investimento público.

1072 Educação \& Realidade, Porto Alegre, v. 40, n. 4, p. 1061-1075, out./dez. 2015. 
Fundamentava-se ainda, essa formação na pedagogia liberal tecnicista e na educação compensatória preferencialmente utilizando a sucata, decorrendo dessa diretriz política, programas assistencialistas voltados, principalmente, às crianças de baixa renda, cuja ênfase colocava-se na alimentação, na higiene e em princípios ideológicos de submissão e de transformação de direitos em dádiva, constituindo discordância frontal em relação aos direitos estabelecidos em diferentes acordos dos quais o Brasil é signatário.

Tem como matriz de formação a teoria do capital humano que produziu uma pedagogia liberal tecnicista cuja ênfase é atribuída ao como fazer - ao invés de ao por que fazer - com orientações muito detalhadas e precisas sobre cada uma das tarefas a serem desenvolvidas, como se a monitora fosse uma tabula rasa, desconsiderando seus conhecimentos e, conforme acima indicado, com quase total ausência da reflexão e a busca necessária de um maior aprofundamento no que concerne à própria concepção de educação e de infância.

A escolha para o desenvolvimento do trabalho com as crianças pequenas recaindo no "monitor" alguém que não atende as exigências legais para o exercício do magistério e na opção pelo treinamento em serviço feito por meio de um periódico são indicadores dessa perspectiva política.

Esta proposta político-pedagógica para as crianças de 4 a 6 anos na época da Ditadura Militar precisa ser veementemente refutada para que se afirme que as crianças são sujeito de direitos, portanto cidadãs que podem e devem dizer a sua palavra, que precisam ser não apenas ouvidas, mas que também se considere o que elas têm a nos dizer.

As professoras precisam ser formadas numa perspectiva de educação emancipatória que promova a igualdade e assim se apropriem de uma postura política e pedagógica que amplie a democracia, ajudem a construir uma educação cidadã que supere o autoritarismo, o adultocentrismo e a discriminação de classe que foi bastante ampliada na época da Ditadura Militar e que ajudou a construir uma política de desigualdade social desde as crianças pequenas.

Recebido em 13 de novembro de 2014 Aprovado em 30 de julho de 2015

\section{Notas}

1 No início da década de 1980, ainda na vigência da Lei 5692/1971 (Brasil, 1971), esse nível de educação sequer era nomeado, visto que estabelecia no art. $19 \S$ $2^{\circ}$ que "Os sistemas de ensino velarão para que as crianças de idade inferior aos sete anos recebam conveniente educação em escolas maternais, jardins de infância e instituições equivalentes".

2 Os demais números da Revista foram publicados por outros órgãos ou instituições.

Educação \& Realidade, Porto Alegre, v. 40, n. 4, p. 1061-1075, out./dez. 2015.1073 
Formação Docente para a Educação Pré-Escolar na Época da Ditadura Militar

3 Aristeo Gonçalves Leite Filho foi Coordenador do Programa Nacional da Educação Pré-Escolar do Mobral nos anos de 1981 e 1982.

4 Revista Criança.

\section{Referências}

BATISTA, Necy Bezerra; BATISTA, Natália Ursulina. Vivemos em grupo... Vivemos em comunidade. Criança, Rio de Janeiro, MOBRAL, n. 3, p. 3, 1983.

BRASIL. Respondendo a sua consulta. Criança, Rio de Janeiro, MOBRAL, n. 5, p. 2, 1983.

BRASIL. Seu dia a dia com as crianças. Criança, Rio de Janeiro, MOBRAL, n. 1, p. 3, 1982.

BRASIL. Lei 5692/1971. Fixa diretrizes e bases para o ensino de $1^{\circ}$ e $2^{\circ}$ graus, e dá outras providências. Diário Oficial [da República Federativa do Brasil], Brasília/DF, 1971. Disponível em: <http://www.pedagogiaemfoco.pro.br/l5692_71. htm>. Acesso em: 05 set. 2013.

BRASIL. Constituição Federal de 1988. Diário Oficial [da República Federativa do Brasil], Brasília/DF, 05 out. 1988. P. 1. Disponível em <http://www.planalto.gov.br/ccivil_03/Constituicao/ConstituicaoCompilado.htm>. Acesso em: 14 set. 2014

BRASIL. Ministério da Educação. Instituto Nacional de Estudos e Pesquisas Educacionais. A Educação nas Mensagens Presidenciais (1890-1986). Brasília: INEP, 1987.

CALMON, João. Memória Viva da Educação Brasileira. Brasília: MEC/INEP, 1991.

CUNHA, Luis Antônio. Roda Viva. In: CUNHA, Luis Antônio; GOES, Moacyr de. O Golpe na Educação. Rio de Janeiro: Jorge Zahar Editor Ltda., 1989. P. 35-94.

DIDONET, Vital. Algumas questões sobre o MOBRAL e a Revista Criança. Entrevista concedida à Ana Maria Orlandina Tancredi Carvalho. Março, 2006.

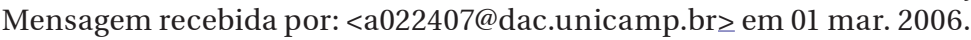

FERREIRA, Marisa Villela Pedras. Brinquedos e Brincadeiras. Criança, Rio de Janeiro, MOBRAL, n. 8, p. 11-14, 1983.

FREITAG, Bárbara. Educação, Estado e Sociedade. São Paulo: Moraes, 1986.

KRAMER, Sonia. Algumas questões sobre o MOBRAL e a Revista Criança. Entrevista concedida à Ana Maria Orlandina Tancredi Carvalho. Março, 2006. Mensagem recebida por:<a022407@dac.unicamp.br $\geq$ em 01 mar. 2006.

KRAMER, Sonia. Privação Cultural e Educação Compensatória. Cadernos de Pesquisa, São Paulo, n. 42, p. 54-62, ago. 1982.

KUHLMANN JR., Moysés. Infância e Educação Infantil: uma abordagem histórica. Porto Alegre: Mediação, 1998.

LEITE FILHO, Aristeo. Algumas questões sobre o MOBRAL e a Revista Criança. Entrevista concedida à Ana Maria Orlandina Tancredi Carvalho. Março, 2006. Mensagem recebida por: <a022407@dac.unicamp.br $\geq$ em 01 mar. 2006.

MARX, Karl; ENGELS, Friedrich. Manifesto Comunista. São Paulo: Boitempo; Jinkings, 1998.

POLETTI, Ronaldo. Constituições Brasileiras: 1934. Brasília: Senado Federal e Ministério da Ciência e Tecnologia, Centro de Estudos Estratégicos, 2001.

1074 Educação \& Realidade, Porto Alegre, v. 40, n. 4, p. 1061-1075, out./dez. 2015. 
ROSEMBERG, Fúlvia. A Educação Pré-Escolar Brasileira durante os Governos Militares. Cadernos de Pesquisa, São Paulo, Fundação Carlos Chagas, n. 82, p. 21-30, ago. 1992.

ROSEMBERG, Fúlvia. As Organizações Multilaterais, Estado e Políticas de Educação Infantil. Cadernos de Pesquisa, São Paulo, Fundação Carlos Chagas, n. 115 , p. 25-63, 2002.

ROSEMBERG, Fúlvia. Sísifo e a educação infantil brasileira. Pro-Posições, Campinas, Universidade Estadual de Campinas, v. 14, n. 1 (40), Campinas, p. 177-194, jan./abr. 2003.

SAVIANI, Nereide. MOBRAL. Escola Municipal, São Paulo, Secretaria Municipal de Educação, Ano 17, n. 12, p. 52-57, 1984.

SOUZA, Solange Jobim. Desenvolvendo o Pensamento da Criança na Pré-Escola. Criança, Rio de Janeiro, MOBRAL, n. 12, p. 3-5, 1984.

THOMPSON, John B. Ideologia e Cultura Moderna: teoria social crítica na era dos meios de comunicação de massa. Petrópolis: Vozes, 1995.

TANCREDI CARVALHO, Ana Maria Orlandina. Políticas Nacionais de Educação Infantil: MOBRAL, Educação Pré-Escolar e a Revista Criança (1982-1985). 2006. 213 f. Tese (Doutorado em Educação) - Programa de Pós-Graduação em Educação, Universidade Estadual de Campinas, Campinas, 2006.

Ana Maria Orlandina Tancredi Carvalho é licenciada em Pedagogia pela Universidade Federal do Pará - UFPA, mestre pela Università Italiana degli Studi di Torino/Itália e doutora pela Universidade Estadual de Campinas - UNICAMP. É Professora Associada 4 da UFPA. Coordena o Grupo de Estudos e Pesquisas em Educação Infantil - IPÊ do Instituto de Ciências da Educação - ICED/UFPA. É Diretora da Faculdade de Educação/ICED/UFPA/Belém. Integra o Fórum de Educação Infantil do Pará- FEIPA e o Movimento Interfóruns de Educação Infantil do Brasil - MIEIB.

E-mail: anatanc@hotmail.com 